\title{
TUBERCULOMA OF THE BREAST; A RARE CLINICAL ENTITY
}

Dinesh. H. N, Madhu. B. S, Karthik Prasad. K, Jaiprakash. H.R, Bharathi.M

1. Associate Professor, Department of Surgery, Mysore Medical College \& Research Institute.
2. Assistant Professor, Department of Surgery, Mysore Medical College \& Research Institute.
3. Post Graduate Trainee, Department of Surgery, Mysore Medical College \& Research Institute.
4. Post Graduate Trainee, Department of Surgery, Mysore Medical College \& Research Institute.
5. Professor, Department of Pathology, Mysore Medical College \& Research Institute.

CORRESPONDING AUTHOR

Dr. Dinesh. H. N

101, Doctors quarters'

Behind MMC ladies hostel

KRS Road Mysore.

E-mail: drdinesh70@gmail.com

Ph: 08212415562,00919448089500

ABSTRACT: Primary tuberculosis of the breast is a rare clinical entity. We report a case of primary breast tuberculosis in a 58 year old lady presenting with palpable lump in the breast with axillary lymphadenopathy, masquerading as carcinoma of the breast. Clinical features are not specific and radiological imaging is of limited value. A cyto-histopathological study for identification of the acid-fast bacilli (AFB) is an important diagnostic tool. Clinical suspicion is important for early diagnosis and appropriate management. Anti-tubercular therapy is the mainstay in treatment and surgery is required only under certain circumstances.

KEYWORDS: Tuberculoma, Mammary tuberculosis, Primary Tuberculosis.

INTRODUCTION: Breast tuberculosis is a rare form of tuberculosis. ${ }^{1}$ The first case of mammary tuberculosis was recorded by Sir Astley Cooper in 1829 who called it 'scrofulous swelling of the bosom'.2 Tuberculosis is a chronic granulomatous disease caused by Mycobacterium tuberculosis.

Involvement of the breast is extremely rare. Its prevalence has been estimated to be $0.1 \%$ of breast lesions examined histologically, and it constitutes about $3-4.5 \%$ of surgicallytreated breast diseases in developing countries. ${ }^{3} \mathrm{An}$ identification of the acid-fast bacilli (AFB) is the key in diagnosis. Anti tubercular therapy is the backbone of treatment of breast tuberculosis. ${ }^{4}$ No specific guidelines are available for the treatment of breast tuberculosis per se.

CLINICAL SUMMARY: A 58 year old lady presenting with a painless palpable lump in the right breast for six months. Physical examination, a non-tender lump occupying entire right breast measuring about $8 \times 6 \mathrm{cms}$, variable consistency with coexisting ulcer and ipsilateral axillary lymphadenopathy.(Figure 1)

Clinically suspecting carcinoma of the breast; mammography was done, which featured multiple round homogeneous opacities in the right breast (BIRADS II) and ultrasound showed multiple collections involving right breast with ductal dilatation which were non-diagnostic and contradictory to the clinical diagnosis.

Cytological examination revealed a caseating tubercular lesion positive for acid fast bacilli in the right breast lump and axillary lymph node.(Figure 2) 
Patient subsequently developed multiple discharging sinuses, confirming the diagnosis. Incisional biopsy was done. Histopathology report was mammary tuberculosis and patient was started on anti tubercular therapy.

Complete evaluation of the patient did not reveal any other primary focus of tuberculosis.

Following one and a half months of anti tubercular therapy, patient developed multiple discharging sinuses involving right breast which was disfiguring, causing distress; hence simple mastectomy was done.(Figure 3 \& 4 )

DISCUSSION: The incidence of isolated tuberculosis of the breast remains low, ranging from $0.10 \%$ to $0.52 \% .^{3}$ It is caused by the acid-fast bacillus, Mycobacterium tuberculosis and though it primarily involves the lungs, any organ in the body can be involved. However, some organs and tissues like the breast, skeletal muscle and spleen are usually resistant to tuberculosis. ${ }^{5}$

Mammary tuberculosis may be primary or secondary and there are three modes of spread;haematogenous, lymphatic or direct spread. ${ }^{6}$ It is mainly seen in women in the reproductive age group, especially affecting lactating females. ${ }^{7}$ Males are rarely affected.

Women in the reproductive age group are at risk as the breast shows periodic changes with menstruation and are more liable to trauma and infection. Pregnant and lactating breasts have increased blood flow and dilated ducts, making them more susceptible to tubercular infection. It is uncommon in prepubescent females and elderly women. ${ }^{8}$

Breast tuberculosis is newly classified as nodular, disseminated, and abscess varieties. The nodular form is the commonest. ${ }^{9}$

The predominant clinical presentation is a breast lump with or without a sinus. ${ }^{6}$

Tuberculoma of the breast most commonly presents as a lump in the central or upper outer quadrant of the breast. It is probably due to frequent extension of tuberculosis from axillary nodes to the breast. Multiple lumps are less frequent. ${ }^{10}$

In our case; patient presented with palpable lump in the breast with axillary lymphadenopathy masquerading as carcinoma. Clinically differentiating from malignancy was challenging, but during hospitalization patient developed multiple discharging sinuses making the diagnosis clear cut with cyto-histopathological correlation. A definitive diagnosis, based on imaging alone, can be difficult to make due to variable patterns of presentation. ${ }^{11}$

A cyto-histopathological study with demonstration of AFB from the breast lesion continues to remain an important diagnostic tool of tuberculoma of the breast.

The treatment of tuberculoma of the breast consists of anti-tubercular therapy and surgery with specific indications; lumpectomy or drainage of the cold abscesses and mastectomy are rarely indicated.

CONCLUSION: Tuberculoma of the breast, though common among lactating and young women, should be an important consideration in differential diagnosis of a breast lump in an elderly lady in our country. Tuberculoma of the breast is an obscure disease often mistaken for carcinoma or pyogenic abscess of the breast, especially if well-defined clinical features are absent. Clinical awareness is necessary for establishing the correct diagnosis and treatment. 
ACKNOWLEDGEMENT: We thank Dr Avadhani K Geeta, Professor of Surgery, Dean and Director, Mysore Medical College and Research Institute, Mysore for her kind support and cooperation.

\section{REFERENCES:}

1. Kalac N, Ozkan B, Bayiz H, Dursun AB, Demirag F. Breast tuberculosis. Breast 2002; 11 : 346-9.

2. Cooper A. Illustrations of the diseases of the breast. Part I. London: Longman, Rees, Orme, Brown and Green; 1829 p.73

3. Hale JA, Peters GN, Cheek JH. Tuberculosis of the breast: rare but still extant. Am J Surg. $1985 ; 150: 620-24$

4. Elmrabet F, Ferhati D, Amenssag L, Kharbach A, Chaoui A. Breast tuberculosis. Med Trop (Mars) 2002; $62: 77-80$.

5. Hamit HF, Ragsdale TH: Mammary Tuberculosis. J R Soc Med1982, 75:764-765.

6. Harris SH, Khan MA, Khan R, Haque F, Syed A, Ansari MM. Mammary tuberculosis: analysis of thirty-eight patients. ANZ J Surg. 2006; 76: $234-237$

7. Zandrino F, Monetti F, Gandolfo N: Primary tuberculosis of the breast. A case report. Acta Radiologica 2000, 41:61-63.

8. Shinde SR, Chandawarkar RY, Deshmukh SP. Tuberculosis of the breast masquerading as carcinoma: a study of 100 patients. World J Surg 1995; 19 : 379-81.

9. D'Orsi CJ, Feldhans L, Sonnenfeld M. Unusual lesions of the breast. Radiol Clin North Am 1983; 21:67-80.

10. Tewari M, Shukla H S. Breast tuberculosis: diagnosis, clinical features \& management. Review Article, Indian J Med Res 122, August 2005, pp 103-110

11. Yuen JHF, Lam TPW, Leong L. Primary Tuberculosis of the Breast. Case report. J HK Coll Radiol 2003;6:33-35

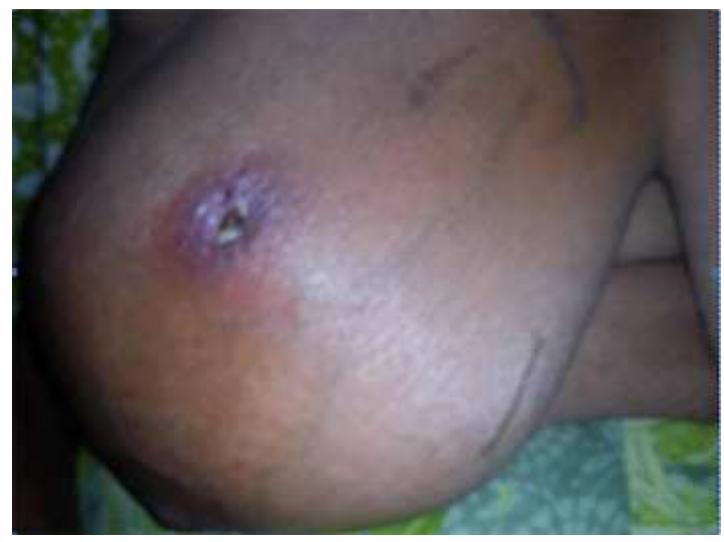

FIGURE 1: Tuberculoma of the right breast, lump in the right breast with discharging sinus and signs of inflammation. 


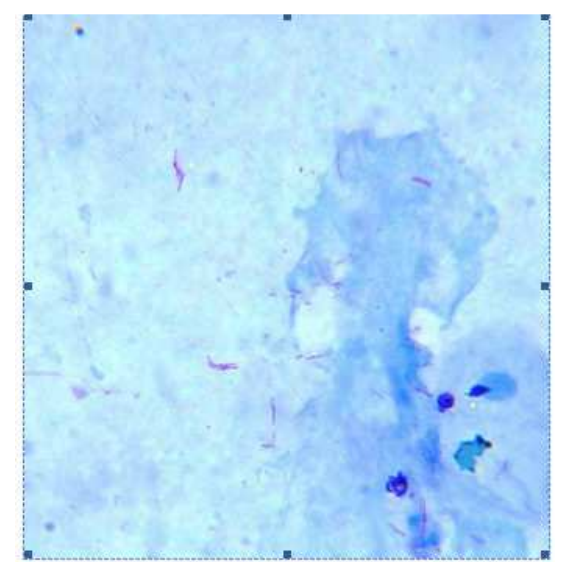

FIGURE 2: FNAC Smear from breast lump showing AFB positive bacilli. (ZN stain X 1000)

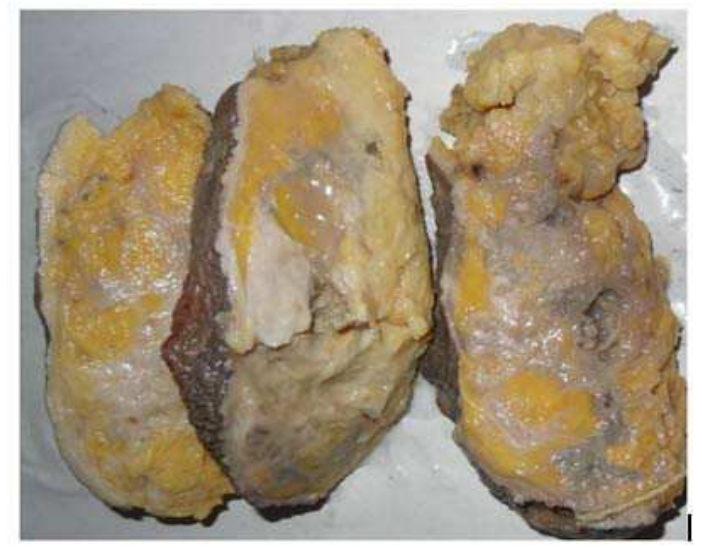

FIGURE 3: Gross sections showing extensive necrosis involving breast tissue with areas of haemorrhage and cavitation.

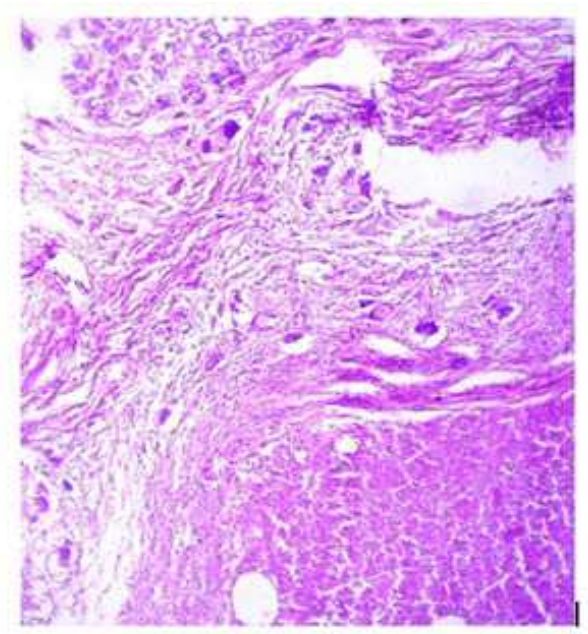

FIGURE 4: HPE- section from the breast mass showing granulomas with central caseation surrounded by Langhans giant cells with periphery showing normal acini. (H\&E X 100) 